\title{
Comparative Analysis of The Attributes in Arabic and Chinese
}

\author{
MAHA MAHMOUD HAMDY MOSTAFA MOHAMED \\ School of International Chinese Studies (SICS) of East China Normal University (ECNU), Shanghai, China
}

\begin{abstract}
Attribute is an important point in grammar knowledge, although it's not a main component, it's just an additional component, but it's a very essential factor. On the contrary, it plays an important role in the expression of semantics, as well as the proper use of attributes, can help us make the expression more accurate. So far, the study based on teaching method which compared Chinese attribute to Arabic doesn't appear in Arabian countries or China. Therefore, studying Chinese language students in which Arabic language is their native language, have many problems when they learn attribute in Chinese language. In this paper we try to find out the differences of the attribute in both languages through the comparative analysis to help us understand the problems which Arabic countries students have while studying Chinese attributes.
\end{abstract}

Keywords: Arabic, Chinese, attribute

\section{The Differences Between Language Type of Arabic and Chinese}

Because of the less development of the comparison between Arabic and Chinese in TCFL, and the two languages belong to different types, which makes a huge difference between syntactic structure of both Arabic and Chinese, Arab students usually have problems while learning Chinese. Languages can be classified according to genealogy. We classify languages of the same origin into the same genealogy. According to the classification of language genealogy, Arabic belongs to the Semitic language family, while Chinese belongs to the Sino-Tibetan language family. According to Professor Wang Dechun's explanation of the classification standard of language types in (the introduction to Linguistics) in 2000, We summarize the characteristics of Arabic and Chinese language types as follows:

Arabic belongs to Inflectional language from the perspective of word structure and morpheme relationship, which is "A construction affix can express several grammatical meanings, and the alternation of morpheme internal sounds can also be used to express grammatical meanings. The affixes and rootsare closely combined" (Wang 2000). For example, "يكتب", (pronunciation: yaktob) is an Arabic word, it doesn't only represent the lexical meaning of "writing", but also represents the third person (He) who performs the action, at the same time it can also express the temporal meaning of "writing". According to the relationship between word structure and morpheme, Chinese belongs to radical language. Words in Chinese "rarely form suffixes, so there are few morphological changes. The relationship between words is generally expressed by word order and auxiliary words” (Wang, 2000). For example, “爸爸爱你，你爱爸爸。” English translation: Dad loves you,

MAHA MAHMOUD HAMDY MOSTAFA MOHAMED, PhD. Candidate, School of Internationl Chinese Studies (SICS), East China Normal University (ECNU), Shanghai, China. 
and you love dad. In this Chinese sentence, the noun “爸爸” “Dad”, the pronoun “你” “you” and the verb “爱” "love" have no morphological changes and do not have any structural suffix. The grammatical relationship between the sentence components is mainly expressed by changing the position of “你” “you” and “爸爸” "Dad" in the word order.

According to the grammatical perspective, Arabic belongs to the synthetic language which "expresses the grammatical relationship between the word and the grammatical function of the word in a sentence" (Wang, 2000), while Chinese belongs to the analytical language which "expresses the grammatical meaning through using word order and auxiliary words" (Wang, 2000).

\section{Definition and Function of Arabic and Chinese attributes}

Wanghuan (1986) pointed out that when we compare the grammar of two languages, we must pay attention to three problems: the first one is to distinguish the concept of grammar and the concept of general thinking; the second one is that the content of the same grammatical term in two languages will not be exactly the same; the third one is that the function of the same kind of words in sentences of different languages is not exactly the same.

In "Modern Chinese grammar speech", Ding shengshu and others classified the modifiers into three categories: (a) noun modifier, (b) verb modifier, (c) adjective modifier. The modifier of a noun is equivalent to an attribute, while the modifier of a verb and the modifier of an adjective together are equivalent to an adverbial modifier. Next, we will take a look at the different definitions and functions of attributes in both Arabic and Chinese language.

\subsection{Definition and Function of Arabic Attribute}

In Arabic, "attribute نعت" refers to a modifier which comes after a noun indicating the characteristics, nature, subordination, quantity, etc. of a person or thing. It can also be called "Adjective صفة" and the preceding noun is called "modificand موصوف". Arabic attribute must be consistent with the gender, number, case and reference of the preceding noun.

The attributive structure in Arabic is different from Chinese, because Chinese attributive structure belongs to endocentric structure. Arabic attributive structure and endocentric structure are two different structures, the attributive structure is premodifier (noun) and modifier (attribute); while the endocentric structure consists of two parts, which are positive part and partial part, the positive part refers to generic noun, while the partial part can refer to definite noun or generic noun, but both of them appear in a genitive status. The function of the partial part is to explain the positive part, and to make the meaning become clearer. For example, كتابُ الطالِب (ketabu el taleb) 学生的书 Student's book (endocentric structure) القَُّ الجَدِيدُ (al qalamo al jadedo) 新笔 New pen (attributive structure). From these two sentences, we can see that the endocentric structure in Arabic has a subordinate relationship, while the attributive structure in Arabic has a kind of quantitative nature relationship.

In Arabic language, words, phrases and sentences can all be used as attributives, words only have nouns which can be used as attributives, and not all nouns can be used as attributives. Attributive nouns mainly are derived nouns, demonstrative nouns and numerals which have the function of adjectives; attributive phrases mainly are spatio temporal phrases and prepositional phrases; attributive sentences mainly are sentences which 
modify generic nouns and sentences which modify definite nouns., but this kind of attributive has a special characteristic, there must be a pronoun between the head noun and the attributive clause, and it must agree in gender and number with the head noun. Chinese grammar generally believes that there is no sentence as an attribute in Chinese, but some researchers suggested that subject predicate phrase can be regarded as a case of attribute in Chinese.

There are two types of Arabic attributive: real attributive, principal and subsidiary attributive. The attributive that directly describes the characteristics and properties of the adjective itself is called the real attributive, while the attributive that indirectly describes the characteristics and properties of people or things related to it is called principal and subsidiary attributive. For example:

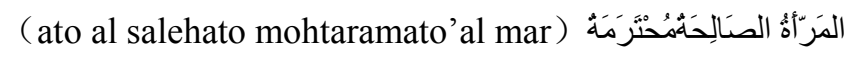

好女人是尊敬的人 The good woman is a respectable person.

\subsection{The Definition and Function of Chinese Attribute}

In "Grammar lecture notes" Zhu Dexi pointed out to Chinese attributive, especially nominals centered modifier. He also added that the attribute which modifies noun is the most typical one, attribute can also modify numeral, quantifier and verb nominalization.

The language unit of Chinese attributive can be divided into two types, which are words (real words) and phrases, such as 蓝天 blue sky, 神奇色彩 magical colors, 女演员 actress (female performer), 戴帽子的男 人 men with hats, 人少的地方 places with few people. From these examples, we can see that Chinese real words which can be modifiers mayinclude nouns, adjectives, quantifiers, pronouns, verbs, etc. most of the words can be attribute. The attributive phrase includes partial positive relation phrase, verb object relation phrase, joint relation phrase, subject predicate phrase, conjunction phrase, the supplementary relation phrase and so on.

According to the meaning relationship between attributive and center word, attributive can be divided into restrictive attributive and descriptive attributive. Restrictive attributive refers to the center words that represent things classification, including nouns, pronouns, adjectives, verbs, etc. For example, 蓝天 blue sky, 镀塑钢 铁构件 coated steel components; while descriptive attributes indicates state or situation of things, it also contains different kinds of emotions, mainly includes the reduplication of adjectives and adjectives with auxiliary elements.

For example, 花儿红红的 the flowers are red (red is duplicated in this example), 树叶已经很绿了 the leaves are very green. The language sign of Chinese attributive is "的" “de", the combination of attributive and center word has different cases, some casesmustadd “的 “de", some cannot add “的” “de”, some others “的” "de" can be added or not. The case of adding “的” “de" depends on the part of speech of the attributive, the syllables number of the attributive center word and the semantic relation between both attribute and center word. The author has summarized the following conditions of adding "的” "de" and not adding "的” "de":

(1) When noun is used as attributive, sometimes we can add “的” “de", sometimes we don't need to add it. For example:

\section{木桌子小的桌子}

Wooden table Or Wooden "de" table 


\section{埃及政府埃及的政府}

The Egyptian government Or The Egyptian "de" government

When "的" "de" is not used, the relationship between the attribute and the central word is closely combined, which is a stableensemble. When "de" is used, the attributive and the central word are a kind of temporary combination, and their independence is relatively large. However, some nouns especially those indicating ownership, “的” “de” must be added it to them. For example: 大卫的铅笔 David's pencil (David "de" pencil).

(2) When adjective is used as attributive, generally monosyllabic adjectives can directly modify nouns, so we don't have to add “的” “de”. For example: 新书 new books, 好人 good person, 高个子 tall personetc. But when disyllabic adjectives, reduplicated adjectives and adjectives with auxiliary elements are used as attributives, we have to add “的” “de”. For example, 漂亮的衣服 beautiful clothes (beautiful “de” clothes), 大大的眼睛 big eyes (big big “de” eyes).

(3) When Personal pronouns: I, you, he, we, you (plural), they etc. are used as attributives, if the central word is relative appellation, or refers to a kind of collective or organization, it is not necessary to add "的" "de". But there are some other cases thatneed “的” “de” to be added, for example, 我的老师 My teacher (My “de” teacher), 他们的学校 Their school (Their “de" school). When demonstrative pronouns and interrogative pronouns are used as attributives, we usually do not need to add “的” “de”. For example: 这个人 This man, 那本书 That book, etc.

(4) When Quantifiers are used as attributives, generally it isn't necessary to add “的” “de". For example: 几本书 several books, 一位老师 a teacher, 七个学生 seven students. But “的” “de” can be added after quantifiers which refers to weights, measures and nouns that used as quantifiers. For example: 一盒香烟 a packet of cigarettes, 一蓝子蔬菜 a basket of vegetable.

(5) Verbs can also be used as attributives. But verbs are just contrary to adjectives, when the monosyllabic verb used as attributive, we need to add “的” “de", otherwise the modifier and the modified phrase will become predicate phrase. For example: 开的车 (Verb+ "de" + modified phrase) the car which was driven, 买的书 (Verb+ "de" + modified phrase) the book which was bought, Only two syllable verbs don't need "的” “de" to be added. For example 学习目标 learning objectives, 参考文献 references.

(6) All kinds of phrases can also be used as attributives, just by adding “的” “de”, for example:

姐姐弟弟的照片

Photos of elder sister and younger brother (nominal conjunctions)

努力工作的男人

Hard working men (verb partial positive phrase)

写完的论文

Finished paper (verb complement phrase)

非常优美的风景

Very beautiful scenery (adjective partial positive phrase)

The attribute is closely related to the structural auxiliary “的" “de". The structural auxiliary "的” "de" is widely used, but using “的” “de" as a sign of attribute is an important usage. It isn't always necessary to add “的” “de” to attributives, adding “的” “de” isn’t always to attributives. For example: 放在桌子上的笔不是你 
的. The pen on the table is not yours. In this example, the first “的” "de" is used after the supplementary phrase, which is a sign of attribute; while the second "的" "de" is not a sign of attribute.

\section{A Comparison Between the Location of Attributive and Central Word in Arabic and Chines}

No matter what kind of language, the positional relationship between attribute and central word is nothing beyond these two conditions: the postpositive attributive which is located after the central language and the prefix attributive which is located before the central language.

Arabic attributive is a postpositive attribute. Please check the following example:

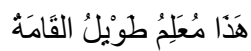

(a) 这是一位高个子的老师（高个子） (老师)

(a) This is a tall teacher (Tall) (teacher)

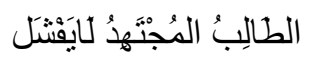

努力学生

(b) 努力的学生是不可失败的 (hardworking) (student)

(b) The hard-working student can't fail.

In Arabic, the modifier which comes after the central word is called attributive, while demonstrative nouns (this, that, these, those, etc.) sometimes are located before the pointed word, sometimes are located after the pointed word. According to Arabic grammar, when demonstrative noun is placed after the pointed word, the demonstrative noun is attribute; but if the demonstrative noun is placed before the pointed word, this demonstrative noun is no longer attribute, instead it's appositive of this pointed word. No matter attributive or appositive, when both are translated into Chinese, they are corresponding to the attributive element in Chinese, which is also inconsistency between Arabic attribute and Chinese attribute due to the limitation of structural form.

Chinese attribute is generally regarded as prefix attribute in Chinese academic circles. Please check the following examples:

(a) (美丽)的城市 beautiful city

(b) (三个)学生 three students

(c) (老师)的作业 teacher's homework

Recently, some scholars think that there are a few numbers of postpositive attributes in Chinese, which are limited to some special expressions. Usually, these postpositive attributes are mostly used as attributes for individual quantitative phrases. Example:

A: 两位吃点什么?

A: what can I have for you?

B: 西红柿鸡蛋一个, 地三鲜一个。

B: one tomato, one egg, and one dish of Sautéed Potato, Green Pepper and Eggplant

The examples of postpositive attribute are limited to oral expressions, and they are very a few. Therefore, overall, Chinese attribute belongs to prefix attribute. 


\section{Conclusion}

In conclusion, Chinese attribute belongs to prefix attribute in most cases, while Arabic attribute belongs to postpositive attribute, this is the biggest difference in form between Chinese and Arabic attributives. This kind

of difference is not very obvious in Chinese single attribute, but when it is necessary to sort Chinese multiple attributes, Arab students might encounter some difficulties.

\section{References}

Deng. J. L. (2017). An analysis of “attributive” in modern Chinese. Beijing: Beijing International Studies University. Isra Abdul Said Hassan. (2001). Examples of improper use of Chinese grammar by Arab students. World Chinese Teaching, (3). Lu, S. X. (1992). A comparative study of grammar. Language teaching and research, (2). 